\title{
Isoniazid Preventive Therapy Adherence and Associated Factors among HIV Positive Patients in Addis Ababa, Ethiopia
}

\author{
Melaku Berhe, ${ }^{1}$ Meaza Demissie, ${ }^{2}$ and Gezahegn Tesfaye $^{3}$ \\ ${ }^{1}$ Research and Training Department, Yeroam Consultancy, P.O. Box 50332, Addis Ababa, Ethiopia \\ ${ }^{2}$ Addis Continental Institute of Public Health, P.O. Box 26751, Addis Ababa, Ethiopia \\ ${ }^{3}$ Department of Public Health, College of Health and Medical Sciences, Haramaya University, P.O. Box 235, Harar, Ethiopia
}

Correspondence should be addressed to Melaku Berhe; melaku_berhe2004@yahoo.com

Received 9 April 2014; Revised 29 June 2014; Accepted 9 July 2014; Published 22 July 2014

Academic Editor: Toru Mori

Copyright (C) 2014 Melaku Berhe et al. This is an open access article distributed under the Creative Commons Attribution License, which permits unrestricted use, distribution, and reproduction in any medium, provided the original work is properly cited.

\begin{abstract}
Tuberculosis coinfected with HIV constitutes a large proportion of patients in Ethiopia. Isoniazid preventive therapy (IPT) is recommended for the treatment of latent tuberculosis infection. However, the level of IPT adherence and associated factors among people living with HIV (PLHIV) have not been well explored. This study aimed to assess adherence to IPT and associated factors among PLHIV in Addis Ababa. Facility based cross-sectional study was conducted. The study was conducted in 10 health centers and 2 hospitals. Patients were consecutively recruited till the required sample size was obtained. From 406 PLHIV approached, a total of 381 patients on IPT were interviewed. Data were entered and analyzed using Epi-Info version 3.5 and SPSS version 16 . The level of adherence to IPT was $89.5 \%$. Patients who have taken isoniazid for $\geq 5$ months were more likely to be adherent than those who took it for $1-2$ months [AOR $(95 \% \mathrm{CI})=5.09(1.41-18.36)]$. Patients whose friends decide for them to start IPT were less likely to be adherent than others $[\mathrm{AOR}(95 \% \mathrm{CI})=0.10(0.01-0.82)]$. The level of adherence to IPT in PLHIV was high. Counseling of patients who are in their first two months of therapy should be more strengthened. Strong Information Education Communication is essential to further enhance adherence.
\end{abstract}

\section{Introduction}

Globally, the number of people living with HIV (PLHIV) continues to grow. According to UNAIDS report, globally, an estimated $35.3(32.2-38.8)$ million people were living with HIV and 1.6 (1.4-1.9) million AIDS related deaths in 2012. Sub-Saharan Africa continues to bear the burden of the global epidemic. A total of 25.0 (23.5-26.6) million people were living with HIV in 2012 in sub-Saharan Africa and an adult prevalence of $4.7 \%$ is reported [1-3].

With an estimated 1.1 million PLHIV, Ethiopia has one of the largest populations of HIV infected people in the world. However, HIV prevalence among the adult population is lower than many sub-Saharan African countries. The national and Addis Ababa adult HIV prevalence in 2010 was estimated to be $2.4 \%$ and $9.2 \%$, respectively $[4,5]$.

TB though curable, it is one of the most common causes of HIV-related illness and death. About 11.5 million adults living with HIV/AIDS are estimated to be coinfected with
Mycobacterium tuberculosis, with $71 \%$ of those coinfected living in sub-Saharan Africa. In Ethiopia, routine data from 44 sites in the year 2005/2006 showed that $41 \%$ of TB patients are HIV positive. Another routine data collected in $2006 / 2007$ showed that coinfection is $31 \%[2,6]$.

HIV is the most important factor fuelling the TB epidemic in populations with a high HIV prevalence. Tuberculosis is the most frequent life-threatening opportunistic disease among PLHIV and remains a leading cause of mortality [7]. Treatment for latent TB infection (LTBI) is an important strategy if tuberculosis is to be eradicated by 2050. It usually consists of 6 to 12 months of isoniazid (INH) preventive therapy (IPT) that has a significant protective effect on those HIV positive clients without active TB by preventing the development of TB disease [8,9].

A significant barrier to effective medical treatment to INH is the patient's failure to follow the recommendations of his or her physician or other healthcare provider. Patient nonadherence sometimes called noncompliance can take 
many forms; the advice given to patients by their healthcare professionals to cure or control disease is too often misunderstood, carried out incorrectly, forgotten, or even completely ignored [10]. Nonadherence carries a huge economic burden. Yearly expenditures for the consequences of nonadherence have been estimated to be hundreds of billions of US dollars. In addition to the most obvious direct costs, nonadherence is also a risk factor for a variety of subsequent poor health outcomes, including as many as 125,000 deaths each year [11].

Several studies reported that nonadherence to therapy is the major problem to control TB in developing countries. The dual infection of tuberculosis and HIV presents further adherence problems because of high pill burden and adverse effects. Adherence to treatment is the key to success [12-14].

However, the level of adherence to IPT and its associated factors among HIV positive patients have not been well explored in Ethiopia. A study conducted in Addis Ababa [15] found out that the level of self-reported adherence rate was $86.5 \%$ which was only limited to hospitals. In addition to hospitals, in this study, we have included health centers to give representative picture of the issue. The information generated from this study is very crucial to provide a basis for possible interventions on $\mathrm{TB} / \mathrm{HIV}$ program and the management of nonadherence to IPT. Therefore, the aim of this study was to assess level of IPT adherence and associated factors among HIV positive patients in Addis Ababa, Ethiopia.

\section{Material and Method}

2.1. Study Setting. A facility based cross-sectional study was conducted in Addis Ababa the capital city of Ethiopia from December 2010 to February 2011. Addis Ababa Health Bureau is responsible for both curative and preventive health care services in the city. There are 10 subcity health departments which are directly accountable to their respective subcity administrations. In the city, there are 24 health centers that are under the Addis Ababa Health Bureau. Totally, there are 38 hospitals in the metropolis. The potential health service coverage in the city is $100 \%$ in terms of availability of the health facilities in a short distance from the community [16].

2.2. Source Population. All HIV positive patients who had been enrolled to chronic HIV care and under IPT in Addis Ababa were the source population.

2.3. Study Population. All HIV positive clients who had beenunder IPT during the study period were the study population. Those patients who were $\geq 18$ years of age, willing to participate, and had taken INH at least for 1 month were included in the study. Those HIV positive patients who are seriously ill were excluded from the study.

2.4. Study Variables. The outcome variable for this study was "Adherence to IPT" which refers to "taking at least $80 \%$ of the prescribed isoniazid doses in the past seven days prior to the survey as reported by the patient" [17]. The independent variables were sociodemographic characteristics, time taken to reach health facilities, waiting time, cost of transport, ART taking status, IPT disclosure status, person who decide to start IPT, chance of getting sick from TB without treatment, attitude on INH which may be dangerous to health, counsel on adherence, duration on IPT, information about INH, and last dose taken.

2.5. Sample Size Determination. The following was the assumption used to calculate the sample size; $Z$ score at $95 \%$ $\mathrm{CI}=1.96, P=$ adherence rate of IPT from a study that was conducted in South Africa was (72\%) [18], and $d=$ margin of error $=4 \%$ which provide a sample size of 484 . When correction formula was applied it gives 369 . Then $10 \%$ none response rate was added which yields a total sample size of 406.

2.6. Sampling Procedure. Ten health centers and 2 hospitals were selected randomly from a sampling frame consisted of a list of all 24 health centers and 5 hospitals that are found under the Addis Ababa Health Bureau. Then, the calculated sample size was allocated proportionally to their size. Based on the inclusion criteria, patients who came for follow up to the health institutions were consecutively interviewed up on their exit to home until the required sample size was obtained.

2.7. Data Collection. The data was collected by using structured questionnaire which was prepared by reviewing relevant literatures and adopted to the study context. The questionnaire was first prepared in English and then translated in to Amharic (local language). The Amharic version was translated back into English to check for consistency and ensure the quality of translation. The data collectors were health professionals that include health officers and nurses who have taken basic TB/HIV and ART training and have experience working in the health facilities.

2.8. Data Quality Control. Training was given for data collectors for two days on how to collect the data. The questionnaire was pretested in $5 \%$ of the sample of people who came to health facilities other than the selected health facilities and amendment was done on the questionnaire. The principal investigator has checked data completeness and consistency on daily basis.

2.9. Data Processing and Analysis. The collected data was checked for consistency and completeness anddouble entered to EPI-Info version 3.5.1 and necessary corrections were made. The data was then exported from EPI infointo SPSS version 16.0 software for analysis and data was summarized using descriptive statistics by running frequencies and the association of dependent and independent variables was evaluated using bivariate and multivariate logistic regression analysis. Those variables that have a $P$ value $<0.2$ in bivariate analysis were further considered in the multivariate logistic regression analysis.

2.10. Ethical Consideration. Ethical approval was obtained from Addis Continental Institute of Public Health and University of Gondar IRB. Addis Ababa Health Bureau wrote support letter to the respective health facilities where the actual study was conducted. Informed consent was obtained from each respondent after explaining the purpose of 
the study. Participant's confidentiality was guaranteed by not recording their personal identifiers on the questionnaire and data was assessed only by the investigators. Their privacy was also maintained by making the interview in a separate place.

\section{Results}

3.1. Sociodemographic Characteristics. Out of the 406 sampled study subjects, a total of $381 \mathrm{HIV}$ positive patients who were on IPT have fully responded to our interview with a response rate of $93.8 \%$. The mean age of the study participant was $35.24( \pm$ SD 8.54$)$ year. Majority of the study participants $265(69.6 \%)$ were females. Nearly half of the respondents, $187(49.1 \%)$, were in the age group of $28-37$ followed by the age group 38-47 that accounted 92 (24.1\%). Majority of the respondents were Amahara, 227 (59.5\%), followed by Oromo, 71 (18.6\%), Tigre, 39 (10.2\%), and Gurage $34(8.9 \%)$ by ethnicity. The predominant religion of the study participants was Orthodox Christian, 317 (83.2\%). One hundred fifty-two (39.9\%) of the respondents have completed primary education. Self-employment is the means of getting income for 170 (44.6\%) of the participants. Most of the study participants, 329 (86.4\%), were living with $\leq 5$ people with them in the same house (Table 1).

3.2. Level of Adherence and Associated Factors. The level of self-reported adherence rate of IPT is found to be $89.5 \%$ with 95\% CI (86.1-92.3). In the bivariate logistic regression, patients who were taking antiretroviral drug were more likely to be adherent $[95 \% \mathrm{CI}, \mathrm{COR}=1.97(1.01-3.84)]$ than patients who were on Pre-ART with $P<0.05$. Respondents who reported to take their pills in the range of $1-11 \mathrm{hrs}$ before the interview were more likely to be adherent than those who did not remember when they took their last dose $[95 \%$ CI, COR = 3.79 (1.49-9.64)]. Respondents who have taken IPT for $\geq 5$ months were more likely to be adherent than those who took for 1-2 months [95\% CI, COR 3.86 (1.2412.00)]. Individuals who were explained about the reasons for taking IPT by their doctors/nurses were found to be more likely to be adherent than those who did not have information why they are taking IPT [95\% CI, COR 6.83 (1.47-31.70)]. Variables such as age, sex, income, time to health facilities, waiting time, ART taking status, disclosure of Isoniazid taking status, and disclosure of HIV status were not found to have significant association with adherence on the bivariate analysis. In the multivariate logistic regression, patients who were on IPT for $\geq 5$ months were more likely to be adherent than those who took it for 1-2 months [AOR $(95 \% \mathrm{CI})=5.09(1.41-18.36)]$. Patients whose friends decide for them to start IPT were less likely to be adherent than those who decide for themselves [AOR $(95 \% \mathrm{CI})=0.10(0.01-0.82)]$ (Table 2).

3.3. Reasons for Nonadherence. Forgetting (45.2\%), drug out of stock $(11 \%)$, side effects $(16.4 \%)$, being too ill to take the drug (16.4\%), patients away from home (5.5\%), and stigma (5.5\%) were among the reasons mentioned by patients for being nonadherent.
TABLE 1: Sociodemographic characteristic of HIV positive patients on IPT in Addis Ababa, 2011.

\begin{tabular}{|c|c|c|c|}
\hline $\begin{array}{l}\text { Variables } \\
(n=381)\end{array}$ & Categories & Number & $\%$ \\
\hline \multirow{2}{*}{ Sex } & Male & 116 & 30.4 \\
\hline & Female & 265 & 69.6 \\
\hline \multirow{4}{*}{ Age } & $18-27$ & 62 & 16.3 \\
\hline & $28-37$ & 187 & 49.1 \\
\hline & $38-47$ & 92 & 24.1 \\
\hline & $\geq 48$ & 40 & 10.5 \\
\hline \multirow{4}{*}{$\begin{array}{l}\text { Level of } \\
\text { education }\end{array}$} & Illiterate & 66 & 17.3 \\
\hline & Primary & 152 & 39.9 \\
\hline & Secondary & 138 & 36.2 \\
\hline & Diploma, and above & 25 & 6.6 \\
\hline \multirow{5}{*}{ Marital status } & Married & 180 & 47.2 \\
\hline & Single & 84 & 22.0 \\
\hline & Divorced & 60 & 15.7 \\
\hline & Widowed & 48 & 12.6 \\
\hline & Separated & 9 & 2.4 \\
\hline \multirow{5}{*}{ Religion } & Orthodox & 317 & 83.2 \\
\hline & Protestant & 32 & 8.4 \\
\hline & Muslim & 27 & 7.1 \\
\hline & Catholic & 4 & 1.0 \\
\hline & Others & 1 & 0.3 \\
\hline \multirow{6}{*}{ Ethnicity } & Amhara & 227 & 59.6 \\
\hline & Oromo & 71 & 18.6 \\
\hline & Tigre & 39 & 10.2 \\
\hline & Gurage & 34 & 8.9 \\
\hline & Sidama & 2 & 0.5 \\
\hline & Others & 8 & 2.1 \\
\hline \multirow{3}{*}{ Family size } & $\leq 5$ & 329 & 86.4 \\
\hline & $6-8$ & 44 & 11.5 \\
\hline & $>9$ & 8 & 2.1 \\
\hline \multirow{3}{*}{ Occupation } & Self-employed & 170 & 44.6 \\
\hline & Employed & 97 & 25.5 \\
\hline & Unemployed & 114 & 29.9 \\
\hline \multirow{4}{*}{ Monthly income } & $<100 \operatorname{ETB}(5.3 \$)$ & 12 & 4.5 \\
\hline & $101-300$ ETB $(5.3-15.8 \$)$ & 71 & 26.6 \\
\hline & $301-500$ ETB $(15.8-26.3 \$)$ & 80 & 30.0 \\
\hline & $>500$ ETB $(26.3 \$)$ & 104 & 39.0 \\
\hline
\end{tabular}

\section{Discussion}

This study has attempted to assess the level of IPT adherence and associated factors among HIV positive patients on isoniazid in selected health facilities of Addis Ababa. This study found an adherence rate of $89.5 \%$. Duration on treatment and decision for initiation of IPT made by friends were factors associated with adherence.

In this study, it was found that $89.5 \%$ of the study participants had taken at least $80 \%$ of their prescribed isoniazid 
TABLE 2: Factors associated with isoniazid preventive therapy adherence among HIV positive patients in Addis Ababa, 2011.

\begin{tabular}{|c|c|c|c|c|}
\hline \multirow{2}{*}{ Variables } & \multicolumn{2}{|c|}{ Adherence } & \multicolumn{2}{|c|}{ OR (95\% CI) } \\
\hline & Yes & No & Crude & Adjusted \\
\hline \multicolumn{5}{|l|}{ Age } \\
\hline $18-27$ & 50 & 12 & 1 & 1 \\
\hline $28-37$ & 171 & 16 & $2.57(1.14-5.78)^{*}$ & $2.13(0.82-5.55)$ \\
\hline $38-47$ & 82 & 10 & $1.97(0.79-4.89)$ & $1.25(0.42-3.71)$ \\
\hline$\geq 48$ & 38 & 2 & $4.56(0.96-21.60)$ & $3.59(0.64-20.34)$ \\
\hline \multicolumn{5}{|l|}{ Sex } \\
\hline Male & 108 & 8 & 1 & 1 \\
\hline Female & 233 & 32 & $0.54(0.24-1.21)$ & $0.43(0.16-1.64)$ \\
\hline \multicolumn{5}{|l|}{ Occupation } \\
\hline Self-employed & 149 & 24 & $0.59(0.27-1.28)$ & $0.40(0.15-1.03)$ \\
\hline Employed & 88 & 6 & $1.46(0.51-4.17)$ & $0.74(0.22-2.47)$ \\
\hline unemployed & 104 & 10 & 1 & 1 \\
\hline \multicolumn{5}{|l|}{ ART taking status } \\
\hline Pre-ART & 100 & 18 & 1 & 1 \\
\hline On ART & 241 & 22 & $1.97(1.01-3.84)^{*}$ & $1.81(0.82-4.01)$ \\
\hline \multicolumn{5}{|l|}{ Last dose taken } \\
\hline $1-11$ & 220 & 16 & $3.79(1.49-9.64)^{*}$ & $2.12(0.75-6.05)$ \\
\hline $12-23$ & 83 & 12 & $1.91(0.71-5.13)$ & $1.39(0.43-4.47)$ \\
\hline$\geq 24$ & 9 & 4 & $0.62(0.15-2.55)$ & $0.26(0.05-1.38)$ \\
\hline Do not remember & 29 & 8 & 1 & 1 \\
\hline \multicolumn{5}{|l|}{ Duration on IPT } \\
\hline 1-2 months & 106 & 15 & 1 & 1 \\
\hline 3-4 months & 126 & 21 & $0.85(0.42-1.73)$ & $0.86(0.39-1.93)$ \\
\hline$\geq 5$ months & 109 & 4 & $3.86(1.24-12.00)^{*}$ & $5.09(1.41-18.36)^{*}$ \\
\hline \multicolumn{5}{|c|}{ Disclosed their IPT taking status } \\
\hline Yes & 245 & 24 & $1.70(0.87-3.34)$ & $1.38(0.63-3.03)$ \\
\hline No & 96 & 16 & 1 & 1 \\
\hline \multicolumn{5}{|l|}{ Information about INH } \\
\hline Yes & 337 & 37 & $6.83(1.47-31.70)^{*}$ & $8.50(0.46-158.25)$ \\
\hline No & 4 & 3 & 1 & 1 \\
\hline \multicolumn{5}{|l|}{ Counseled on adherence } \\
\hline Yes & 338 & 38 & $5.93(0.96-36.61)$ & $1.03(0.03-31.42)$ \\
\hline No & 3 & 2 & 1 & 1 \\
\hline \multicolumn{5}{|l|}{ Made decision to start INH } \\
\hline The patient & 102 & 5 & 1 & 1 \\
\hline Family & 6 & 1 & $0.29(0.03-2.93)$ & $0.99(0.07-13.68)$ \\
\hline Friends & 6 & 2 & $0.15(0.02-0.92)^{*}$ & $0.10(0.01-0.82)^{*}$ \\
\hline Doctors/nurses & 227 & 32 & $0.35(0.13-0.92)$ & $0.46(0.14-1.47)$ \\
\hline \multicolumn{5}{|c|}{ INH may be dangerous to your health } \\
\hline Strongly agree/agree & 85 & 18 & $1.02(0.38-2.62)$ & $1.05(0.32-3.46)$ \\
\hline Strongly disagree/agree & 223 & 15 & $3.15(2.00-8.31)^{*}$ & $3.16(0.95-10.54)$ \\
\hline Do not know & 33 & 7 & 1 & 1 \\
\hline \multicolumn{5}{|c|}{ Chance of getting sick from TB without treatment } \\
\hline High & 225 & 23 & $1.76(0.77-4.04)$ & $1.88(0.70-5.06)$ \\
\hline Average/below average & 66 & 8 & $1.49(0.54-4.12)$ & $1.12(0.33-3.77)$ \\
\hline Do not know & 50 & 9 & 1.00 & 1.00 \\
\hline
\end{tabular}

${ }^{*}$ Statistically significant. 
doses in the past seven days prior to the study. This was almost similar to a study in Addis Ababa, Cambodia, and Diredawa, $86.5 \%, 86 \%$, and $84.9 \%$, respectively $[15,19,20]$. This study has shown higher level of adherence to IPT when compared with a study that was conducted in Uganda, 62\% [21]. This adherence level variation may be explained by the fact that the study in Uganda was conducted many years ago when the integration of TB/HIV services may have not been developed as the current situations and it might also be attributed to the difference in method of assessment which is refilling of medicines used in Ugandan study. In another study that was conducted in South Africa, the adherence rate was 72\% [18] which is also lower than this study. This may be because the level of adherence in the South African study was measured by more objective method that involved a biochemical test called the Arkansas method, where a chemical reaction with urinary INH metabolites produces a visible blue color change and self-report method. In general the level of nonadherence $10.5 \%$ is good and acceptable when compared with other studies reported having so far nonadherence level ranging from 14 to $38 \%$ [19-24].

In the multivariate analysis, patients who took IPT for $\geq 5$ months were more likely to be adherent than those who took it for 1-2 months. This finding is paradoxical with a study conducted on latent tuberculosis prevention therapy in Latino immigrants [25] in which adherence dropped from $98 \%$ in month 2 to $72 \%$ at 9 months which means that patients at the initial were more likely to be adherent than at the end of the treatments. This variation could be explained by the fact that the repeated counseling services that the patient got from the health facilities during their long follow up period would probably make them more adherent. In this study, patients who made the decision to start IPT by friends were less likely to be adherent than those who made the decision by themselves. This implies that patients may start to take INH because of peer influence but they may fail to adhere to treatment because of lack of knowledge or self efficacy by themselves.

In this study, the predominant reason for not adhering to IPT was forgetting to take pills. This finding is consistent with several other studies conducted on adherence for longterm treatments and also for tuberculosis preventive therapy. In a study that was done in Dire Dawa, (21.2\%) of the study participants were reported to have missed doses as a result of forgetting [19]. The same was true in a study that was conducted in Addis Ababa; [15] 24.24\% of the study participants mentioned forgetfulness as a reason for missing doses. It implies that there is a requirement for a program that strengthen the adherence of patient through memory aids. The other reason for nonadherence mentioned by patients was unavailability of drug at the health facility. This was the case also in South Africa [18] where peripheral pharmacy sometimes runs out of INH and, as a result, 10 (55.6\%) patients were forced to miss doses. In this study, $12.96 \%$ of the respondents had reported that they missed doses because of the side effects of the drug. In Tanzania, 14\% of individuals had side effects and as a result they were forced to miss doses and considered as nonadherent [26]. The other reasons mentioned were patients become too ill to take INH and patient is away from home which is similar to another study [23].

The strength of the study is that since there is only few previous studies done in the area, the result of this study could be used as a baseline for program implementation. The limitation of this study includes the fact that adherence level was assessed by self-report which is subjected to recall and social desirability biases and, as a result, level of adherence could be overestimated and at the same time association could be underestimated. The other limitation was the fact that no standard questionnaire was used for the study and there could be clustering of patients at the level of health facility due to the nature of the sampling technique used.

In conclusion, the level of adherence for IPT is high. Patients who took INH for $\geq 5$ months were found to be more likely to be adherent than those who took it between 1 and 2 months. Patients who made the decision to start IPT by friends were less likely to be adherent than those who made the decision by themselves. Among the reasons mentioned for being nonadherent, forgetting was the predominant one. Counseling should focus on patients who are in first and second months of followup. Availing cellular phone alarms as reminders, memory aids like diary card, and watches for alarming treatment times for the patients is crucial.

\section{Conflict of Interests}

The authors declare that there is no conflict of interests regarding the publication of this paper.

\section{Authors' Contribution}

Melaku Berhe has initiated the study and performed the overall design and execution of the study, data collection, and statistical analysis. Meaza Demissie has participated in the revision of the design of the study and data collection techniques and helped in the statistical analysis. Gezahegn Tesfaye has participated in the drafting of the paper and took part in the critical revision of the paper. All authors read and approved the final paper for submission.

\section{Acknowledgments}

The authors would like to acknowledge data collectors and study participants. They also would to extend their gratitude to Addis Ababa Health Bureau for permitting them to undertake the study and for their kind cooperation throughout the study.

\section{References}

[1] WHO and USAID, Core Epidemiology Slides, Global Summary of the AIDS Epidemic 2012, 2013.

[2] WHO, Guide Lines for Implementing Collaborative TB and HIV Programme Activities, World Health Organization, Geneva, Switzerland, 2003.

[3] UNAIDS, "Global report on the global AIDS epidemic," 2013.

[4] Federal Democratic Republic of Ethiopia and Federal HIV/ AIDS Prevention and Control Office, "Report on Progress 
Towards Implementation of The UN Declaration of Commitment on HIV/AIDS," Addis Ababa, Ethiopia, 2010.

[5] Federal Minstry of Health \& Federal HIV/AIDS Prevention and Control Office, Single Point HIV Prevalence Estimate, Addis Ababa, Ethiopia, 2007.

[6] Federal Ministry of Health, Tuberculosis, Leprosy and TB/HIV Prevention and Control Programme Manual, Federal Ministry of Health, Addis Ababa, Ethiopia, 4th edition, 2008.

[7] Federal Minstry of Health, TB/HIV and Leprosy Prevention and Control Strategic Plan, Federal Minstry of Health, Addis Ababa, Ethiopia, 2007-2009.

[8] WHO, TB/HIV Clinical Manual, 2004.

[9] WHO, Three I's Meeting, World Health Organization, Geneva, Switzerland, 2008.

[10] L. Martin, S. Williams, and R. Dimatto, "The challenge of patient adherence," The Clinical Risk Management, vol. 1, no. 3, pp. 189199, 2005.

[11] E. Vermeire, H. Hearnshaw, P. van Royen, and J. Denekens, "Patient adherence to treatment: three decades of research: a comprehensive review," Journal of Clinical Pharmacy and Therapeutics, vol. 26, no. 5, pp. 331-342, 2001.

[12] International AIDS Society-USA, "Tuberculosis and HIV in the Caribbean: approaches to diagnosis, treatment, and prophylaxis," Topics in HIV Medicine, vol. 12, no. 5, pp. 144-149, 2004.

[13] WHO, Interim Policy on Collaborative TB/HIV Activities, Geneva, Switzerland, 2004.

[14] M. G. Amuha, P. Kutyabami, F. E. Kitutu, R. Odoi-Adome, and J. N. Kalyango, "Non-adherence to anti-TB drugs among TB/ HIV co-infected patients in Mbarara Hospital Uganda: prevalence and associated factors," African Health Sciences, vol. 9, supplement 1, pp. S8-S15, 2009.

[15] M. Mindachew, A. Deribew, F. Tessema, and S. Biadgilign, "Predictors of adherence to isoniazid preventive therapy among hiv positive adults in Addis Ababa, Ethiopia," BMC Public Health, vol. 11, article 916, 2011.

[16] Addis Ababa City Adminstration Health Bureau, Operational Manual for Regional HIV/AIDS Care and Treatment Catchments Team Activities, Addis Ababa City Adminstration Health Bureau, Addis Ababa, Ethiopia, 2010.

[17] D. A. Mitchison, "How drug resistance emerges as a result of poor compliance during short course chemotherapy for tuberculosis," International Journal of Tuberculosis and Lung Disease, vol. 2, no. 1, pp. 10-15, 1998.

[18] T. A. Szakacs, D. Wilson, D. W. Cameron et al., "Adherence with isoniazid for prevention of tuberculosis among HIV-infected adults in South Africa," BMC Infectious Diseases, vol. 6, article 97, 2006.

[19] D. Taddesse, Assesement of IPT Implementation, Adherence and its Determinats in the Public Health Facilities of Diredawa UOG/ACIPH, 2009.

[20] B. S. Sutton, M. S. Arias, P. Chheng, M. T. Eang, and M. E. Kimerling, "The cost of intensified case finding and isoniazid preventive therapy for HIV-infected patients in Battambang, Cambodia," International Journal of Tuberculosis and Lung Disease, vol. 13, no. 6, pp. 713-718, 2009.

[21] T. Aisu, M. C. Raviglione, E. van Praag et al., "Preventive chemotherapy for HIV-associated tuberculosis in Uganda: an operational assessment at a voluntary counselling and testing centre," AIDS, vol. 9, no. 3, pp. 267-273, 1995.
[22] M. L. Garcia, J. L. Valdespino, C. Garcia-Sancho et al., "Compliance and side effects to chemoprophylaxis for TB in HIV+ Mexican experience," in Proceedings of the International Conference on AIDS, 9 (324), abstract no. PO-B07-1133, 1993.

[23] J. Ngamvithayapong, W. Uthaivoravit, H. Yanai, P. Akarasewi, and P. Sawanpanyalert, "Adherence to tuberculosis preventive therapy among HIV-infected persons in Chiang Rai, Thailand," AIDS, vol. 11, no. 1, pp. 107-112, 1997.

[24] M. Bakari, A. Moshi, E. A. Aris et al., "Isoniazid prophylaxis for tuberculosis prevention among HIV infected police officers in Daresalaam," East African Medical Journal, vol. 77, no. 9, pp. 494-496, 2000.

[25] R. L. Ailinger, J. B. Moore, N. Nguyen, and H. Lasus, "Adherence to latent tuberculosis infection therapy among latino immigrants," Public Health Nursing, vol. 23, no. 4, pp. 307-313, 2006.

[26] P. J. Munseri, E. A. Talbot, L. Mtei, and C. F. Von Reyn, "Completion of isoniazid preventive therapy among HIV-infected patients in Tanzania," International Journal of Tuberculosis and Lung Disease, vol. 12, no. 9, pp. 1037-1041, 2008. 


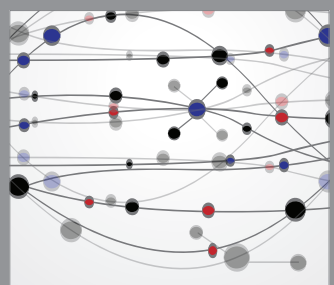

The Scientific World Journal
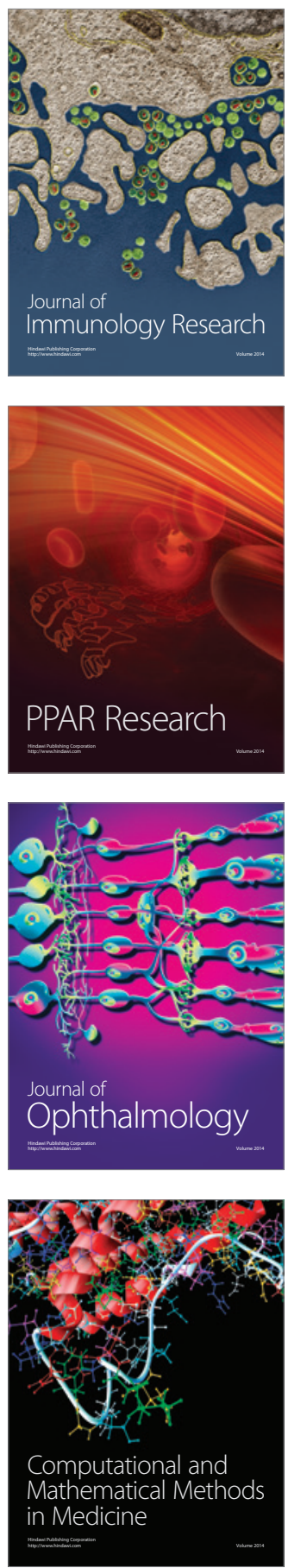

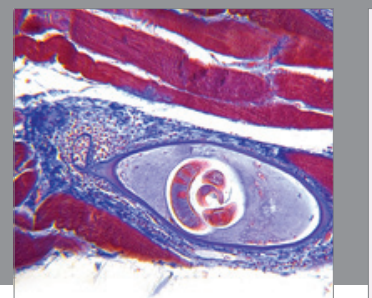

Gastroenterology

Research and Practice
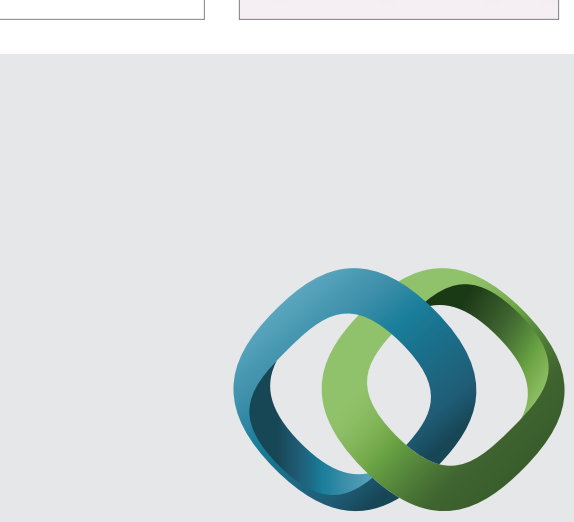

\section{Hindawi}

Submit your manuscripts at

http://www.hindawi.com
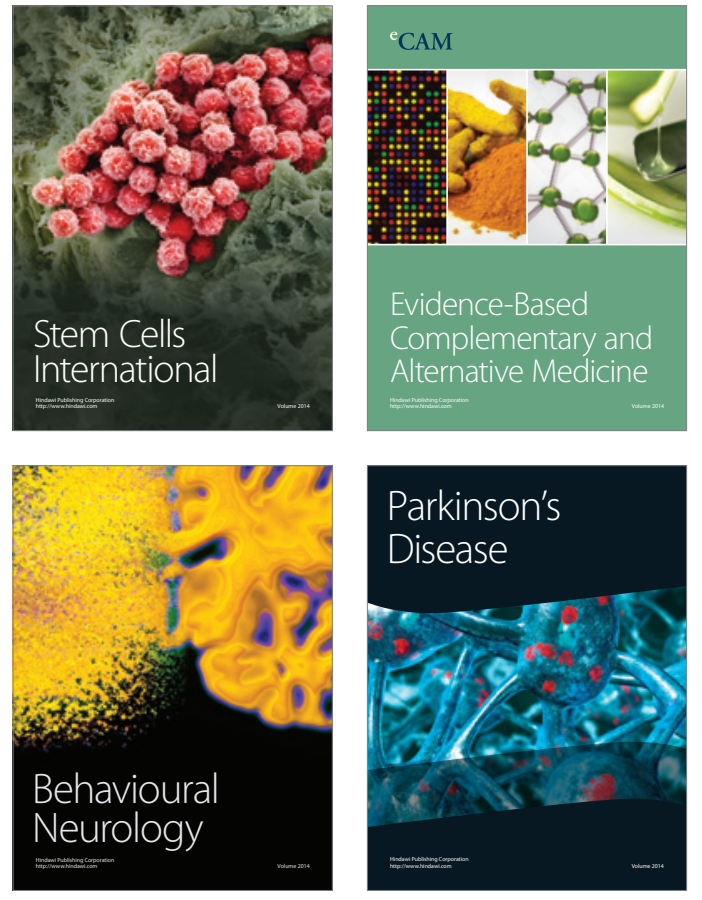
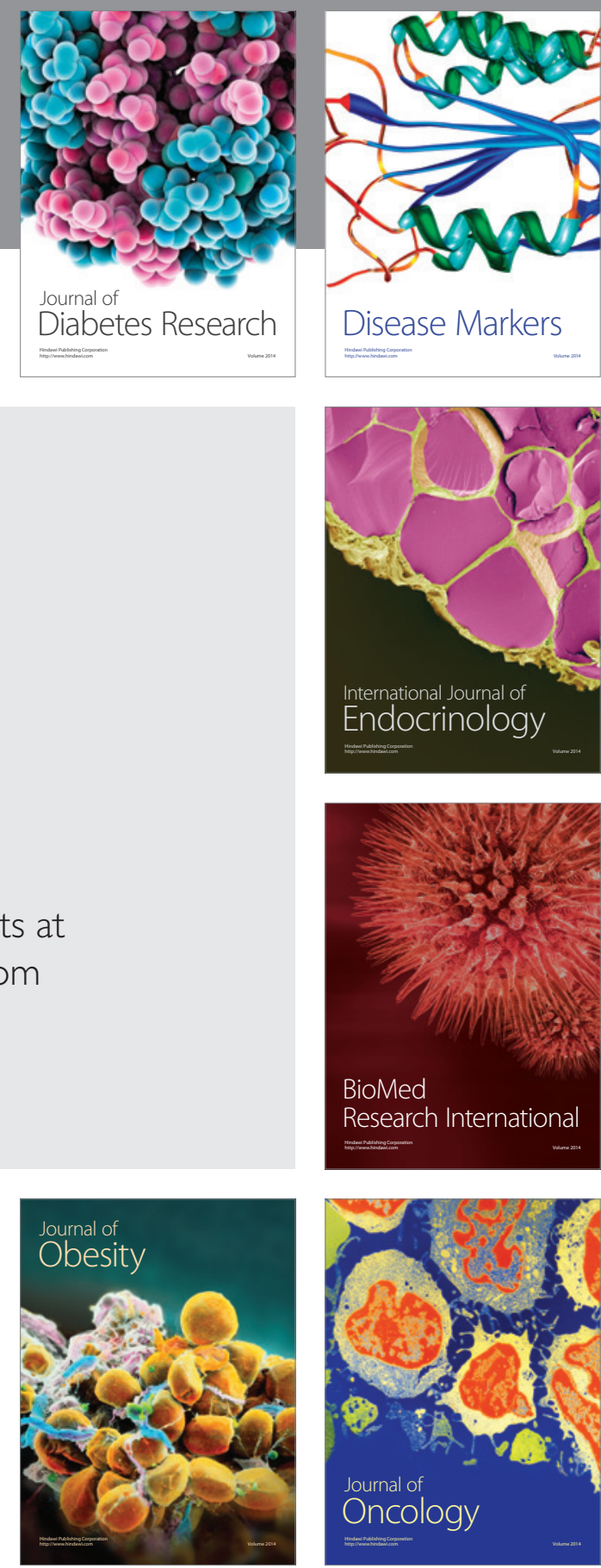

Disease Markers
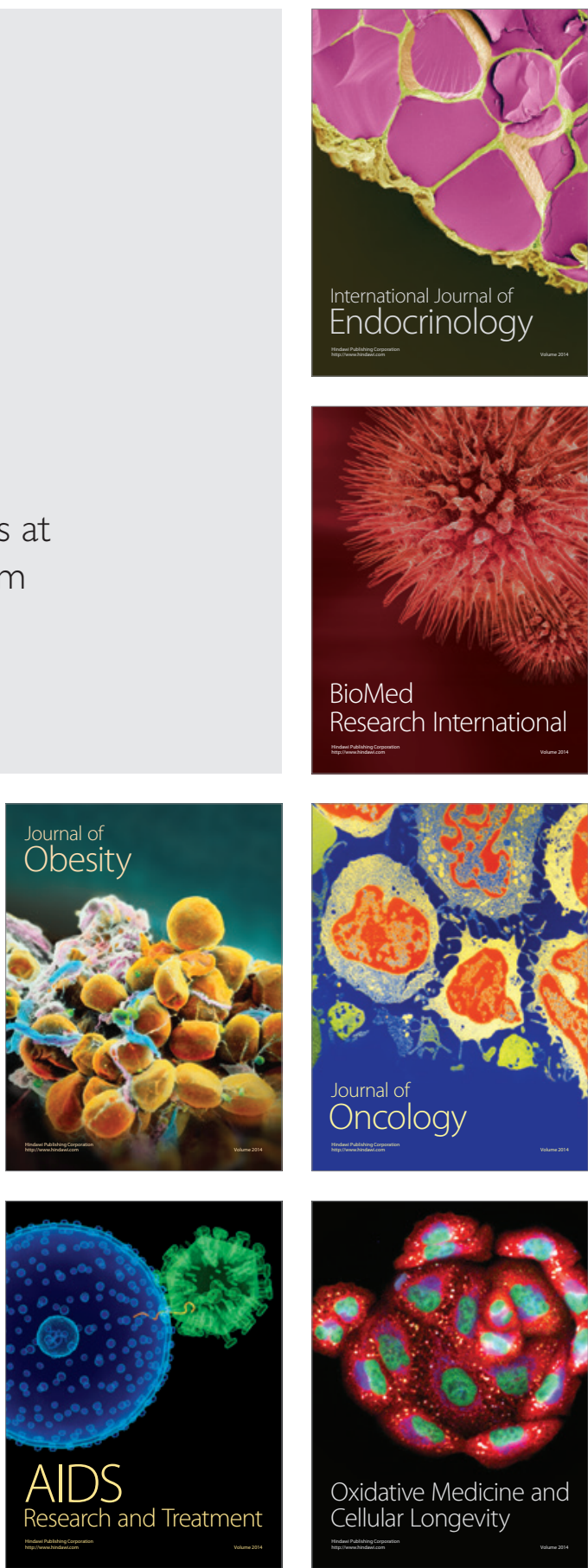